\title{
CONTROL SYSTEM APPROACHES FOR SUSTAINABLE DEVELOPMENT AND INSTABILITY MANAGEMENT IN THE GLOBALIZATION AGE
}

\author{
A. Talha Dinibütün ${ }^{1}$, Reinhard Neck ${ }^{2}$, Johan Stahre $^{3}$, \\ Georgi M. Dimirovski ${ }^{1,4}$, Ljubisa B. Vlacic ${ }^{5}$, Frederick Kile ${ }^{6}$ \\ ${ }^{1}$ Dogus University, Faculty of Engineering, \\ Acibadem, Kadikoy, TR-34722 Istanbul, Turkey \\ Emails: \{gdimirovski,talhad\}@dogus.edu.tr \\ ${ }^{2}$ University of Klagenfurt, Dept. of Economics, \\ JosefstadterStr. 87/34, A-1080 Wien, Austria \\ Email: reinhard.neck@uni-klu.ac.at \\ ${ }^{3}$ Chalmers University of Technology, Human Fact.Eng. \\ S-41296 Gothenburg, Sweden \\ Email:johan.stahre@hfe.chalmers.se \\ ${ }^{4}$ SS Cyril and Methodius University, El.Eng. Faculty \\ Karpos 2 BB, MK-1000 Skopje, Rep. of Macedonia \\ ${ }^{5}$ Griffith University, Nathan Campus, \\ Intell. Con. Sys. Lab, Brisbane Qld 4111, Australia \\ Email:L.Vlacic@griffith.edu.au \\ ${ }^{6} 420$ E, Sheffield Lane, Appleton, Wisconsin, \\ WI 54913-718,USA, Email: fkile@new.rr.com
}

\begin{abstract}
Mankind civilization in the globalization age depends heavily on advanced information technologies resulting from automation of control and decision expertise and their respective scientific disciplines. These have a multitude of impacts on development of national economies within the global economy. The broad area of social systems, being essentially human centred systems, is a cross-, inter- and multi-disciplinary challenge to control community. Social systems in modern civilization, currently undergoing globalization, are reviewed from the systems science viewpoint and on the grounds of recent developments in control science and technology. Recent developments put new emphasis on the social responsibility of the control and automation field during the ongoing changes from the cold-war bipolar world to a unipolar one on the way to mankind's multi-polar world of the future. The focus should be on innovative systems approaches, employing new paradigms, to combined knowledge and technology transfer world-wide, that may remedy some of the negative aspects of globalization. Copyright $@ 2005$ IFAC
\end{abstract}

Keywords: Developing countries, education, human centred systems, globalization age, instability management, knowledge and technology transfer, society, systems approaches.

\section{INTRODUCTION}

To the memory of Michel Cuénod, Harold Chestnut, and John F. Coales

In the year of the previous IFAC World Congress, UNESCO (2002) announced the publication of its Encyclopaedia of Life Support Systems (EOLSS) as presenting: “... a comprehensive, authoritative and integrated body of knowledge of life support systems. It is a forward-looking publication, designed as a global guide to professional practice, education, and heightened social awareness of critical life support issues...". Their definition begins with the sentence "A life support system (LSS) is any natural or human-engineered system that furthers the life of the biosphere in a sustainable fashion" and planet Earth is observed as depicted in Figure I. The EOLSS, in some way, has included some 10 subject categories dealing with topics on control, decision and management in systems engineering within its 21 


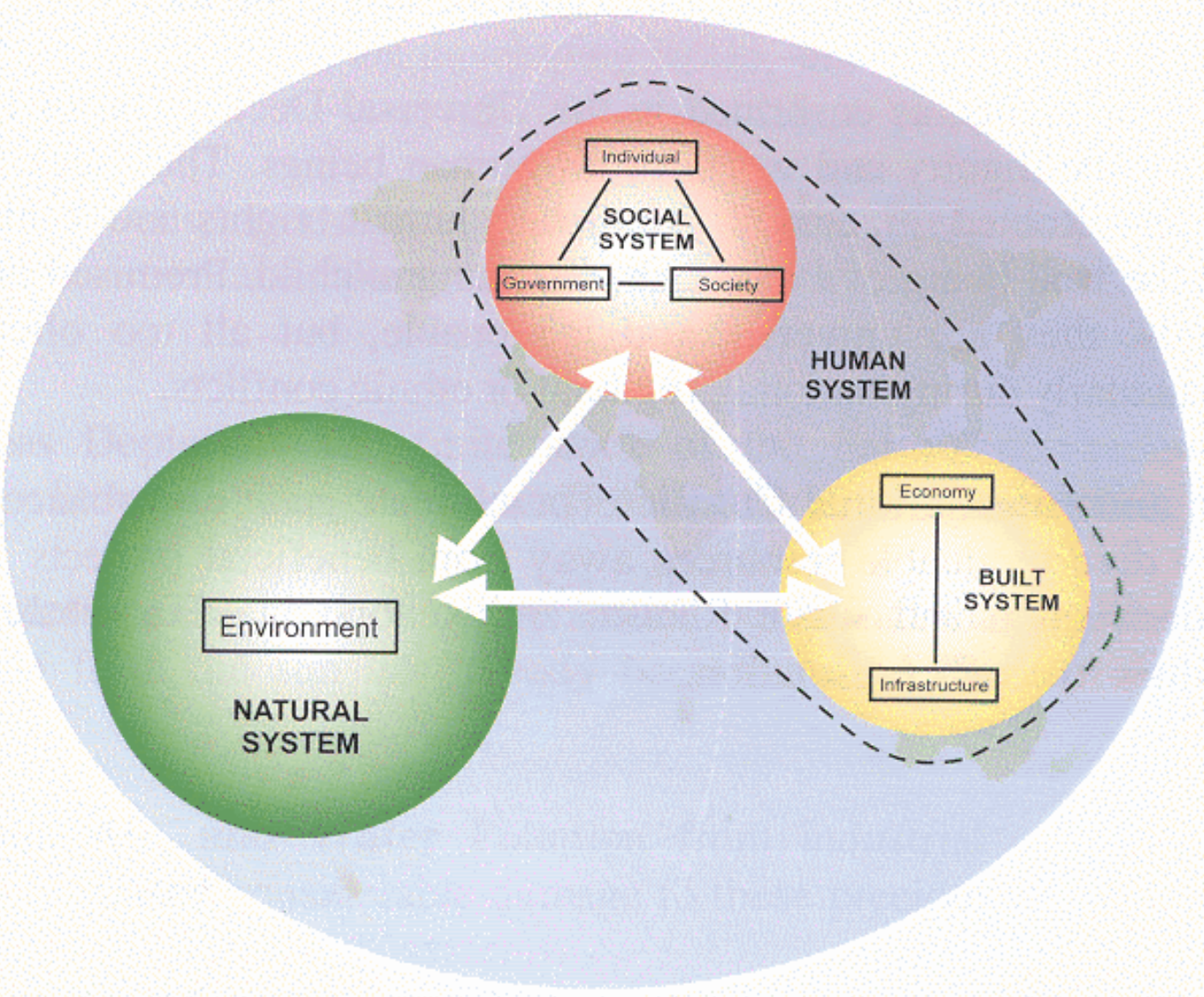

Fig. I. Conceptual model of the Earth's global system (EOLSS, 2002).

main themes, while only one theme is devoted to Physical Sciences, Engineering and Technology Resources. In addition, it should be noted that the quality of human resources is defined via education, health, poverty, dis advantaged people and human resource management. Furthermore, one of the six goals forming the basis for the design of EOLSS reads " $\ldots$ to elucidate sustainable development, peace, justice, equity and global security...", which clearly supports the opinion put forward in this milestone report.

It is well known that since the early days of cybernetics that systems and control science can indeed be effectively applied to socio-economic and socio-technical systems (Aldrich, 1979; Cuénod and Kahne, 1973; Stinchcombe, 1990), which make a category of systems that are human and society centred (see Figure I). This is so because systems and control science (Beniger, 1986; Buchanen, 1982; Gardner, 1985; Groumpos, 2000) can be used to solve diverse problems (Gibson and co-authors, 1997) of decision, control, management, planning, and stability of organizational systemic structures (Chestnut, 1984; Giocoechea and co-authors, 1982; Coales and Seaman, 1995; Kilgour and co-authors, 1987; Pete and co-authors, 1998; Stinchcombe, 1990; Schefran, 2001; Wagner, 1994) that emanate from contemporary civilization and all of its lifesustaining activities. As pointed out in (Dimirovski, 2001a; Mansour, $2001 \mathrm{a}, \mathrm{b}$ ), this describes a rather broad category of systems that are not amenable to pure mathematical modelling and pure mathsanalytical study but rather to a consortium of relevant scientific disciplines and methods (also, see Bitanti and Picci, 1996; Dormido and Morilla, 2002; Martensson and Cernetic, 2002; Neck, 2003; Vlacic and Brisk, 2001).

Nonetheless, to this date, many system science based studies related to social systems have assumed a fixed, stable background. This implies that a number of society factors (some discussed in more detail below) can safely be overlooked or cannot be accounted for by quantifiable methods. However, assumptions that imply a static system model and environment are unsound, particularly if these assumptions are contrary to the facts. Sound assumptions have to observe: (i) The global environment is changing (e.g., per capita resource availability is declining); and (ii) If not addressed, these factors may exacerbate international instability and could trigger new forms and modes of global and regional instability. For instance, many actions, undertaken globally in the 20th century, to reduce socio-economic imbalances postponed problem 
solutions rather than creating alternative social behaviour likely to reduce underlying problems. Such circumstances call for new paradigms for studying the social effects of technology, in general, and automation, control, and systems engineering technology, in particular. Currently, the prevailing paradigm for studying the effects of technological change is based on assumptions that have lessened in the recent past. At the same time, modern media has raised personal expectations for more people than ever before. Questions have arisen as follows: Is it possible to distribute the perceived benefits of new technologies as rapidly as the demand for these benefits is increasing? Since new technologies place new demands on the environment, can these demands be met, given environmental and resource considerations? Recall the impact of earlier technological advances such as Gutenberg's movable type or radio and television as an engine for popular dispersal of information but also as an instrument of propaganda, or the "home computer" that was a "toy" less than 25 years ago and now is a widely used tool for the distribution of information. Often their consequences have far exceeded early expectations accompanying each new advance. Profound social developments have been created by advances once viewed as curiosities or even as "toys". Yet, it is only recently that documents produced for engineering organizations have begun to address social expectations while nowadays social expectations for technology have also to undergo modifications.

The rest of this milestone report is written as follows. The social, ie., socio-economic and socio-technical, systems are explored in here. Section 2 is devoted to shedding new light on understanding the recent background of present-day social systems and the underlying phenomena. Section 3 presents the current key problems of this technical area. Section 4 discusses some recent major achievements and observed trends. In Section 5, some more important forecasts for the immediate future are put forward. Conclusions and references follow.

\section{TOWARDS UNDERSTANDING THE BACKGROUND OF CONTEMPORARY SOCIAL SYSTEMS}

No doubt, the social impact of automation on the modern civilization of mankind has been enormous during the past decades and considerable investigation has taken place (Beniger, 1986; Martensson and Cernetic, 2002; Gardner, 1985). Contemporary civilization, while entering the $21^{\text {st }}$ century and the globalization age, has faced a remarkably negative civic reaction, which is growing and expanding rapidly as the actual globalization process develops and as the related political and scientific discussion forums expand (Dinibütün and Dimirovski, 2001; Kile, 2001, 2004; Kopacek and
Stapleton, 2004). Wherever world-wide political forums have taken place, there is widespread antiglobalization protest with sometimes dramatic international participation. This negative civic reaction is not only internationalised, but getting more and more organised so that rumours about any kind of anti-globalisation movement spread worldwide. Yet, it might be argued that the process of world-wide interaction and integration of economies (Glenn and Hannan, 2000) and other life-sustaining activity areas of contemporary societies actually is the current and inevitable stage of the historical development (Dimirovski and Dinibütün, 2003) of mankind. Moreover, it can be argued that it is, in the first place, due to the impact of information-based technologies within which control and decision technologies play a crucial role (Brandt and Cernetic, 1998; Brandt and co-authors, 1999; Dimirovski, 1988; Kopacek, 2002; Kosko, 1993; Luenberger, 2002; Special issue on Neural Networks, 2001; Neck, 2003; Stahre and Martensson, 2004).

A logical question arises: Why is such a growing internationalised and negative civic reaction taking place? Why does this lead to potential global conflict?

First, it should be noted that the structural model of human behaviour is a feedback-feedforward one involving both mind and emotions (Mansour, 2001a), and this reflects upon social groups and entire societies. Hence, similar structural models (Harary and co-authors, 1965) intrinsic to human and society centred systems, are induced in various types of social system problems such as those depicted in Figure II (Dimirovski, 2001a). The main consequence is that human centred systems are rather complex systems with a diversity of dynamic phenomena (Dimirovski, 2001a; Mansour, 2001a). Secondly, it should be noted that the world is about systemic structures that are inherently non-causal systems. Furthermore, these are only partially identifiable, only partially observable and are likely to be only partially controllable (Dimirovski, 2001a; Mansour, 2002). Moreover, the world encompasses a network of interacting systems, typically neither well-defined nor well-structured, that constitute the background of relevant research and become the basis for major conclusions and results (Dimirovski and Dinibütün, 2003; Kile, 2004; Kopacek, 2004; Mansour, 2002) in the areas of social systems.

It may well be argued that world-wide, 15 years after the end of the so-called bipolar world during the Cold War era, general public awareness is shifting towards a critical perception of modern civilization as a unipolar world (Kile, 2004; Schefran, 2001; Wagner, 1994) endangered by negative global consequences such as environmental pollution, global warming, the so-called "north-south gap", and terrorism. Even some kind of global dictatorship cannot be excluded, the systemic structure of which 
remarkably resembles such known events in developed countries in the not so distant past (e.g., see Mansour, 2001b, 2002). One reason for this development is the fact that modern civilization is largely European lead, on the grounds of past colonial expansion, with western oriented legal systems prevailing almost world-wide.

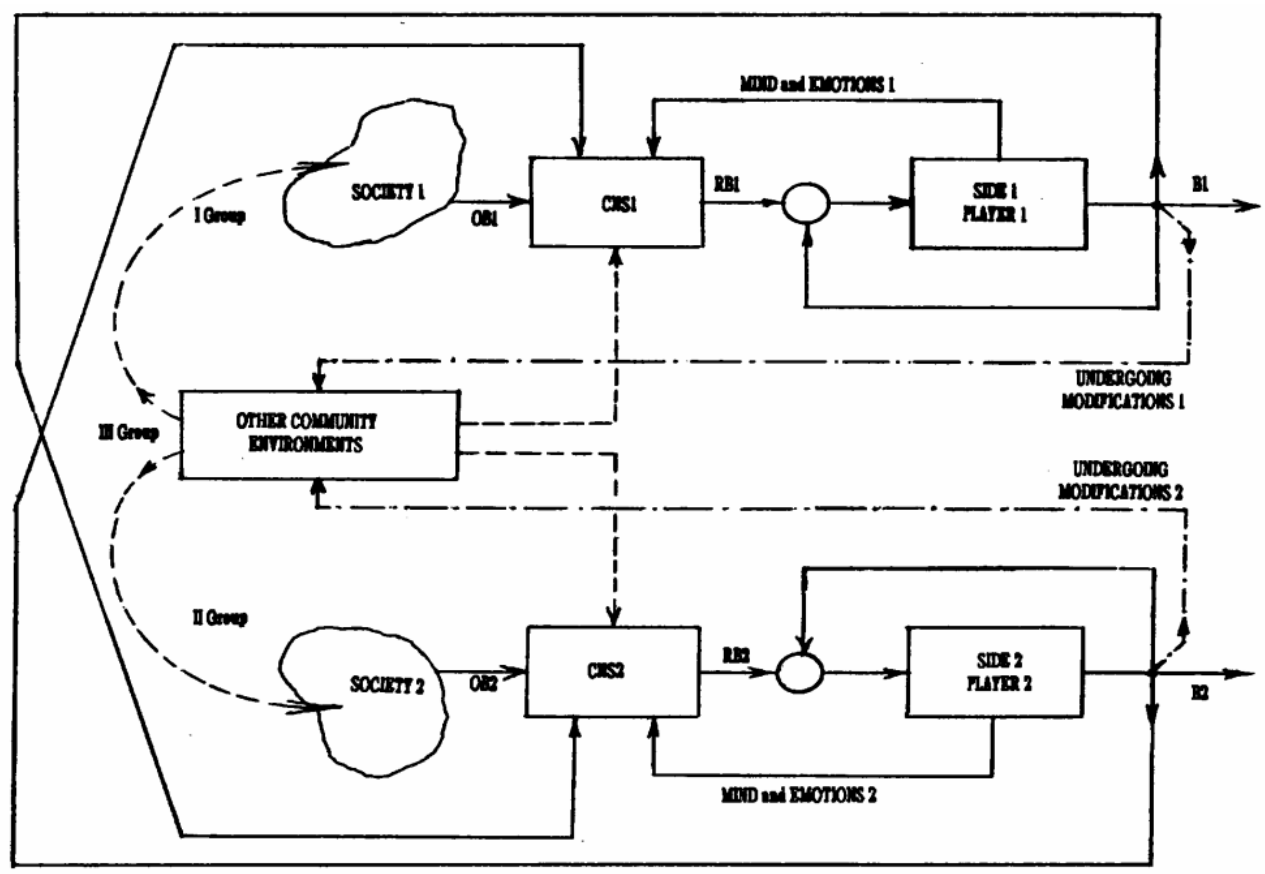

Fig. II. Societies of modern civilization in the globalization age as a multi-loop feedback-feedforward structural model allowing for game theory applications: A system analysis result (Dimirovski, 2001a).

This has left a heritage of so-called "developing" or Third-World or "disadvantageous" countries. Nowadays, more than ever before, the responsibility of scientists with respect to society world-wide, in general, and developing countries, in particular, is rightly justified given the actual behaviour of modern civilization within the societies for which legislation continues to expand relative to ethics (Figure III) (Hersh, 2001; Hersh and Tucker, 2004; Mansour 2002).

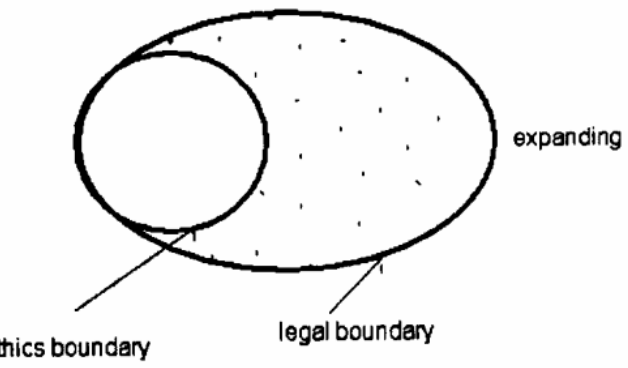

Fig. III. Ethical versus legislative behaviour in societies of the modern civilization (Mansour, 2002).

As pointed out by Mansour (2001b), according to Bertrand Russell, a fundamental concept in social science and philosophy as well as in human societies is power (Russell, 1945, 1975) with its many forms: civil authority, military, propaganda, secret service, clergy, and - above all - wealth. This fact and the need for competition in human societies (Axelrod, 1997; Eeckhout, 2000) as well as other factors of western social philosophies, largely adopted worldwide, are inducing potential for conflict thus producing social system behaviour and structure resembling inefficient non-cooperative games (e.g., Kilgour and co-authors, 1987; Myerson, 1991).

Considerbly early on, Harold Chestnut and John F. Coales recognised that systems approaches can provide a deeper understanding, can facilitate the development of improved procedures for managing destabilizing conflicts and hence improve international stability (Chestnut, 1984; Coales and Seaman, 1995). I general, science and technology have a crucial impact on all these forms of power. For all forms of power have been and are generated via some kind of organizational system. The impact of the advanced fields of information-based systems and control science as well as the respective control and management decision technologies, albeit hidden (Astroem, 1999), has been and still is essentially instrumental in all forms of power (Mansour, 2002). Recent social developments have emphasised this impact of control and decision technologies (Dimirovski and Dinibütün, 2003).

Therefore the world-wide community of systems and control scientists and engineers also has a social responsibility to search and find sets of answers to 


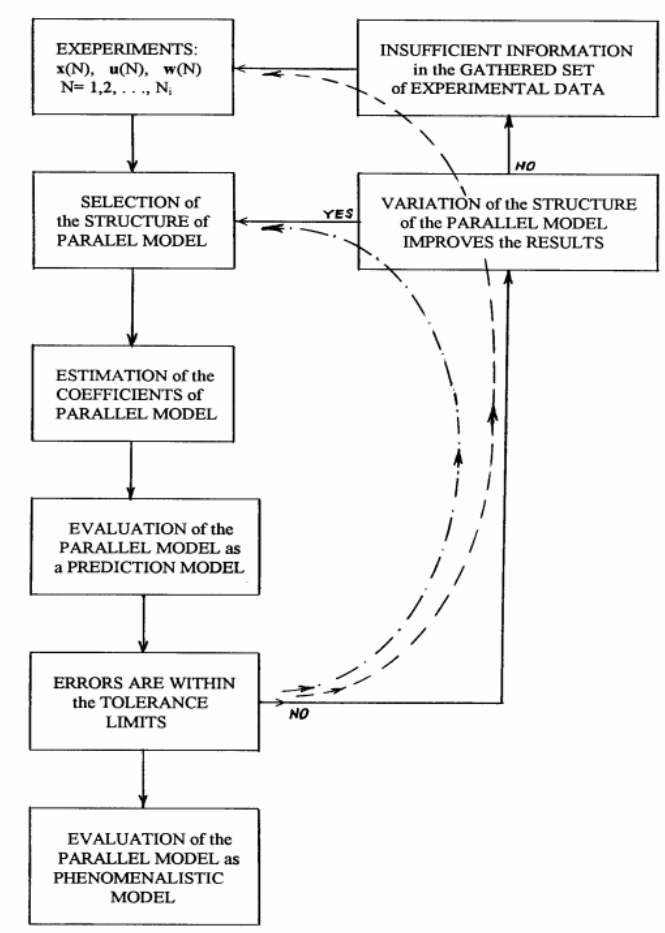

Fig. IV. Phenomenalistic system model identification (Mansour, 2001 a).

issues related to the above questions. The widely important potential benefits of knowledge and technology transfer were clearly foreseen by Michel Cuénod and Stephen Kahne (1973), who were and remain the early promoters of the idea that such processes could influence positively not only developing countries but human civilization at large.

It may be argued, with good reasons, that searching for a proper understanding of the globalization process and for justifiable ways and means of enhancing the positive effects and suppressing the negative ones is concerned largely with combined knowledge and technology transfer to disadvantageous countries (e.g., see Bloch, 2000; Craig and Camisani-Calzolari, 2001; Dinibütün and Dimirovski, 2003; Kopacek and Stapleton, 2004). In addition to these issues, criteria like accountability, ethics, fairness and justice (Mansour, 2001 a), and ethical requirements in research work (Hersh and Tucker, 2004) have to be observed. It is therefore that the phenomenalistic (Figure IV) the structural modelling (Figure II) are rather useful in applications of systems and control science to social systems.

\section{KEY PROBLEMS IN SOCIAL, SOCIO- ECONOMIC AND SOCIO-TECHNICAL SYSTEMS}

At first glance, it may seem that key problems of concern are of a somewhat "new-old" nature. For these are focused on known ideas of using selected branches of control system technology (Cuénod and Kahne, 1973; Dimirovski and Istefanopulos, 2004; Groumpos, 2000; Kopacek, 2004 b; Sgurev and coauthors, 2004) to address issues and find some resolution in areas like the following: improving business processes; increasing the economic efficiency of manufacturing production while saving energy and reducing environmental pollution; enhancing progress in developing countries; improving international stability; using systems and control education to assist more efficient society development and so on.

However, it appears that current problems are less due to the fact that mankind's bipolar world has disappeared and a multi-polar one has not yet been created, but rather due to an interim series of ongoing transition crises. Moreover, considerable opposition against the globalization process has been generated despite the fast progress of global networking of societies and all aspects of their lifesustaining activities: from banking and financial processes to manufacturing and production and further to communication and transportation (Ilyasov, 2000; Kopacek, 2004 b, Sgurev and coauthors, 2004; Zaremba and co-authors, 2004). Another reason for this situation is a generic one: in some cases, phenomenological system identification has found successful applications to human and society centred systems (Mansour, $2001 \mathrm{a}$, b; see Figures IV, VII), and it appears that not all system and control theories are equally applicable. Nonetheless, the concepts, models and methods of systems and control science, culminating in the principle of feedback (e.g., see Figure V), may serve the purpose of systematically organized state transitions of human and society centred systems to attain desirable efficient and/or productive states, albeit possibly with a long transition time scale depending on the class of social system investigated.

Ideas of using knowledge from control theory in economics in order to analyse and design systems in decision making, management and planning é.g., Aldrich, 1979; Gibson and co-authors, 1997) have emerged in the early days of cybernetics and later developed in several scientific disciplines and technologies (Buchanen, 1982; Gioechea and coauthors, 1982; Levin and co-authors, 1992). The area of socio-economic systems, in particular banking and business processes and enterprise organizations as well as their operations, recently have undergone fundamental changes: (a) On the one hand, they are becoming more and more trans-national due to capital mobility and global networking (e.g., Glenn and Hannan, 2000; UNESCO, 2002). (b) They begin to employ highly sophisticated decision support systems (e.g., see Luenberger, 2002; Kosko, 1993) based on computational intelligence (Special Issue on Neural Networks, 2001; Zimmermann, 1998), and they shift towards networks of co-operating or competing small-and-medium enterprises (SME; 
Kopacek, 2004 a). Apparently, new paradigms nowadays characterise these socio-economic system structures, and this is a rather strong trend likely to continue for quite some time (Neck, 2003).

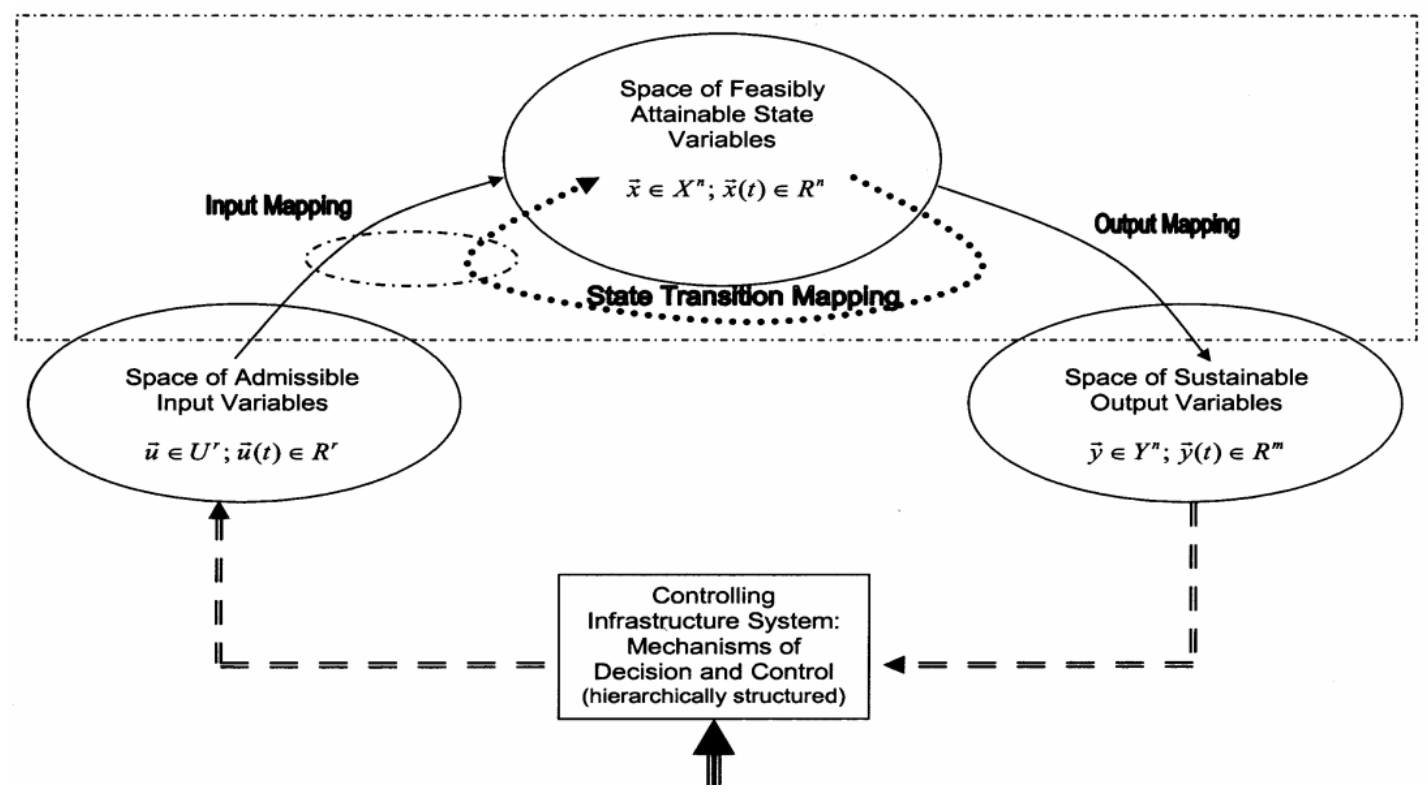

Fig. V. A generic conceptual model using general systems theory in engineering terms for state transitions in social (human and society centred) systems by virtue of controlling feedback infrastructure; applicable to society transitions in developing countries by enhancing infrastructure development (Dimirovski, 1988).

In the case of SME, in particular, increasing the enterprise efficiency, flexibility, and market responsiveness to adjust to requirements of modern supply chain dynamics and the respective management is closely related to the problems of improving the business process. It should be noted that in the area of decision and control for economic systems and business processes (see also Figure V) as well as modelling of the respective dynamics, a deep shift towards computational intelligence methods (e. g., see Pete and co-authors, 1998; Special Issue on Neural Networks, 2001; Wang and Archer, 1998; Yager, 2004) is under way, along with the newest theoretical advances in methodologies for dealing with perceptions and "computing with words" (Zadeh, 1996, 1999, 2002) in computing machines. Moreover, these developments are likely to lead to new uses of qualitative information (e.g., Zadeh, 1984; Gardenfors, 2000) in decision and control techniques for systems with a distributed information base and partially decentralis ed control system architectures. In addition, increasing economic efficiency of production in manufacturing while saving energy and reducing environmental pollution (Bernhardt and Erbe, 2002; Zaremba and co-authors, 2004) corresponds directly to decision and control for business processes and economic systems.

Over several decades, there has been a high level of research interest in developing methods and models based on system and control science for applications to manage risks and improve international stability within the setting of a dominantly bipolar world (Chestnut, 1984; Coales and Seaman, 1995; Kilgour and co-authors 1987; Myerson 1991). The current globalization process, however, has opened new and challenging problems in the transition to a multipolar world and the management of conflicts and crises that are different from those in more recent times (Dimirovski, 2001 a; Kile, 2001, 2004; Schefran, 2001). In the longer term, these are largely concerned with issues of how technology can contribute to reducing conflict risks and improving international stability (Kopacek, 2002; Kopacek and Stapleton, 2004). Also the question arises as to how advanced decision and control theories can be adjusted to decision analysis applications in social systems (Kopacek, 2004 b) in general and to conflict management and resolution (Kile, 2001, 2004) in particular. For instance, consider a small set of developments in the global natural environment and society which have occurred in recent decades, some of which continue into the present. These developments, according to the time frame of their major impacts, may be loosely classified into two types (Kile, 2004): (a) background changes already seen as destabilizing; (b) trends which may cause future destabilization. However, some deep research is needed to understand, and not solely identify, the latter.

More than 20 years have elapsed since the first dedicated event devoted to exploring supplemental ways for conflict management and improving international stability took place using methods of 
systems science (Chestnut, 1984). Some of the topics in this technical area are worth noting, having been compiled from the literature: cultural, political, educational, behavioural, and legal aspects of international stability; techno-economic conditions for international stability; systems analytical approaches; mediation and negotiation in conflict resolution; decision making processes and the respective modelling. By and large these are as relevant today as they were in the past. However, at present, the new paradigms that characterise the unipolar world point to the whole spectrum of complexities in this regard (Axelrod, 1997; Kile, 2004; Küng, 1990), which are yet to be studied and innovative methods developed and applied.

It may be observed that the issues of decision and control applications to enhance accelerated but sustainable progress in developing countries towards proper and fruitful use of automatic control technologies are somewhat specific (Dimirovski and Istefanopulos, 2004; Sgurev and co-authors, 2004). It should be noted that this is a process that is not yet entirely understood and still remains somewhat vague, although structural models like those in Figures II, IV and V may illustrate many features of subjects and topics of research in this field. It seems as if globalization has given increased priority to the development process issues of mankind's presentday societies. In order to support this statement, consider two cases of infrastructure systems (Dimirovski, 2001 b) that are highly dependent on the quality of automation and control technology embedded therein and are also safety-critical. Observe first the case of air traffic control and management: regardless of whether it concerns a highly developed, developing or under-developed country, air traffic control and management is a globalized system and must function according to the requirements of safety-critical systems everywhere. Next, observe the case of rapidly evolving telecommunications: apart from the purely technical aspects of a highly complex and automated network system, the management and operation of transnational (globalized) economic systems essentially depend on communications, and they have become rather vulnerable in this infrastructure. At this point, let us recall some of the main topic areas of conferences and papers on system approaches to developing countries: management and development policies; agriculture and food; power; water and pollution control; urban planning, transport and communications; gas, oil and cement industries; methodologies; education and health; human resources; and, finally, international cooperation and development. It should be noted that, by and large, these are as relevant today as they were in the past. Therefore "IFAC-DECOM" objectives have been formulated and aim at promoting the development of control and automation and related systems and control topics in developing countries as well as enhancing knowledge and technology transfer for their sustainable development. The aim is to support economic progress and improve the quality of life in these countries by making a positive impact to enhance productivity, reliability and safety within the areas of industrial processes and infrastructure systems. Thus it is argued that innovative explorations are needed in order to establish system approaches and means of using automation and control technology to facilitate socio-economic development and enhance technological progress in developing countries, hence contribute to improving international stability (Kopacek, 2002). Furthermore, it may be argued that the extent to which "developing countries" objectives will be accomplished also depends on some kind of cooperative forum with other applications oriented technical areas where decision and control are crucial for their sustainable operation (Dimirovski and Istefanopulos, 2004; Kopacek, 2004; Sgurev and co-authors, 2004). In particular, the word is about cost-oriented automation, power plants and systems, transportation systems, and agriculture.

During the last couple of decades, in general, education has been recognised world-wide as the crucial tool for the development of societies towards improving the quality of human resources and the quality of life itself (Martensson and Cernetic, 2002). Education in automatic control is part of this crucial tool, which guides future generations into information-based high-level technologies (Vlacic and Brisk, 2001). There are two related issues of concern: on the one hand, how can control education be made more effective and beneficial; and on the other hand, how can control be utilised to assist society to better develop its resources and potential. This is an area that has received particular attention world-wide during the last two decades, and its developmental prospects have been well established (e.g., see the 2003-2004 Issues of Euro. J. of Eng. Education and of IEEE Trans. on Education). The series of dedicated IFAC symposia and workshops have addressed almost every envisaged issue and topic of education and training in systems and control theory and engineering, as well as issues concerned with the future needs and developments in both basic and advanced control education. Recently, topics of control education and training have included: development in control laboratories; remote laboratories and experiments; simulation and animation on the web; challenges to control engineering curricula; teaching control theory; teaching advanced courses in control; software tools for control education; possibilities of computer networks in training; web courses in control; etc. (Dormido, 2002; Mishau and co-authors, 2001). In the past, these symposia have been largely defined and designed so as to face the timely challenges emerging from advances in theory, applications and technology of control systems. Nonetheless, further improvements are needed in teaching techniques, more-effective teaching laboratories, internet based 
learning, etc., on the one hand and on the other hand, further explorations of the effective role of international inter-university consortia (Romanovsky and co-authors, 2004; Kopacek, 2004 b) and of creating and running virtual departments in systems and control engineering (Rudas and co-authors, 2001; Dimirovski, 2004 b).

The actual impact of automation on society so far experienced has suggested that some of the problems should be revisited because of the evolved knowledge on human-machine systems and human skills based automation (Stahre and Martensson, 2004). These research activities have evolved so as to encompass all issues and topics of the social impact of automation from ergonomic design of engineering work to human-oriented manufacturing systems and enterprise redesign. In brief, over time these IFAC activities have enhanced the development of several distinctive system approaches in this field: traditional techno-centric approach; human centred approach; socio-technical approach; and some specific approaches such as change management, success factors, and ethical issues. The milestone paper by Martensson and Cernetic (2002) presents a thorough overview analysis as well as forecasting for the future, and therefore there is no need for more elaboration of this area here. However, the inter-related topics of the social impact of automation and cost-oriented automation, which are likely to have rather strong mutual impact, are in the early stages of investigation and open up prospects for future innovative results and technologies.

\section{SOME MAJOR RECENT ACCOMPLISHEMENTS}

Education is essential for the overall development of the control field. Hence control education has undergone considerable evolution in order to cope with the advances in both the theory and technology of the field. From the initial focus on interactive computer-assisted teaching and training through computer-assisted learning and self-tuition, nowadays the focus of control education has shifted to studies of contemporary challenges of internetbased learning and training as well as to life-long learning (Dormido and Morilla, 2002; Gentil, 2004; Lindfors, 2004). Recently, topics of control education and training have included: developments in control laboratories; remote laboratories and experiments; simulation and animation on the web; challenges to modern curricula in control theory and engineering; teaching techniques for control theory; teaching advanced courses in control; web based courses in control; possibilities of computer networks in training, etc. Also, it is worth noting that recent conferences and workshops run by most organizations dedicate one or two sessions to specific educational tasks and/or problems (e.g., see
Dimirovski, 2001 b; Kopacek, 2004 c), thereby giving cross-fertilised contributions to the technical area of control education.

Knowledge in the area of international stability in mankind's societies world-wide, when observed as a system of interacting sub-systems, in particular, versus the issues of global development, has considerably advanced since the early 1980s. In fact, this study observation has yielded a deeper and more subtle insight into the difficulties as well as the limitations in applying results of the formal control theories. In this area of control applications, by and large, the investigations have been focused on models and methods of conflict management and resolution (Buchanen, 1982; Dimirovski 2001 b; Kile, 2001; Kilgour and co-authors, 1987; Mansour, 2002; Myerson, 1991), most of which employ noncooperative game theory and dynamic group decision analysis.

The bipolar world, for which most of the knowledge on applications to international stability has been developed, however, has been replaced by a world largely in a series of transition crises, in which the accelerating pace of change and the conflicting access to technology of communities and societies have become more typical features (Axelrod, 1997; Dimirovski, 2001 a; Eeckhout, 2000; Kopacek, 2002; Schefran, 2001). An additional characterizing pattern of activities, that of striving to gain technology by any means and at any cost, has become apparent (Kile 2004; Wagner, 1994). If the current pattern of activities continues, it will certainly amplify societal and economic instability. For the sake of clarity and the scope of this document, let us mention two simple examples: "If my colleagues and I help to automate a facility, what will the impact be on workers, the community, and this industry?" "If we (the engineering community) build this guidance system, will warfare become even more destructive?" All of us have seen drafts of "Codes of Ethics for Engineers" (Martin and Schinzinger, 1996; Hersh, 2001). The weakness of these codes has been in their complexity and even more so in how to ensure these codes are observed. What the engineering community does indeed demand is a strong social commitment - "First, do no harm" -, perhaps even more so than in the medical profession. Engineers are even more challenged to devote resources, both monetary and intellectual, to guiding the course of future technological developments so as to enhance social stability or to observe the road to active peace (Kile, 2001, 2004), and not just conflict management and resolution. Each example suggests that "technical solutions" to socio-economic and socio-political problems are often inadequate in accounting for interactions among background conditions, socioeconomic variables and societal behaviour. 


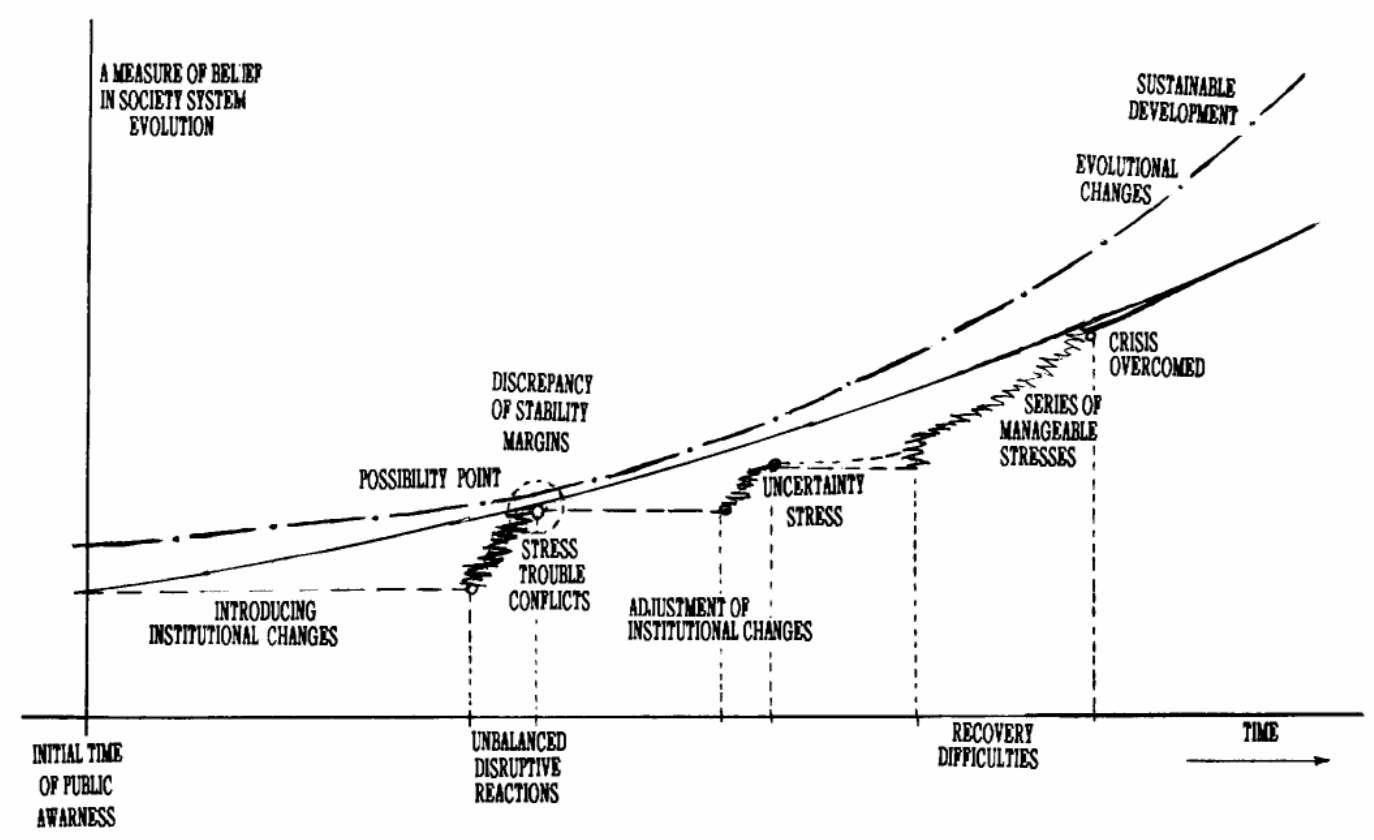

Fig. VI. Developmental dynamics of transitional crisis process in Southeast-European countries: in 15 years only Slovenia has reached the state 'crisis overcome' (Dimirovski, 2000 a).

The above analysis shows that mankind's worldwide societies in the globalization age indeed is in transition towards a supposedly stable multi-polar world of the future. In addition, it should be noted that contemporary rather closely interacting and interconnected societies, which is supported by tremendous technology advances in the past century, have dramatically shortened the dominant time scale of the dynamics of society development (Dimirovski and Dinibütün, 2003). It should be observed that only to a certain extent systems science approaches have been used to clarify how transition crises occur and evolve. For the sake of better understanding this point, let one system-science based result on the dynamics of structural changes caused by a serious crisis that dramatically changes societies be mentioned here. The word is about transitional crisis of Southeast-European countries. It may well be summarized in an illustrative way as depicted in Figure VI above.

Considerable light on the potential and the specifics of systems science applications to social systems has been shed by Mansour (2001 a, b; 2002). For instance, let observe his results on qualitative modelling of dictatorial governing regimes in a country (Figure VII). Structural model of dictatorial regime that was/is typical for a contemporary developing country (e.g., Third World) is depicted in Figure VII a. Similarly, structural model of dictatorial regime that was/is typical for a developed country (e.g., in Europe and Latin America) is depicted in Figure VII b. It is apparent, the applied systems science captures well the main features, respectively, into structural models.

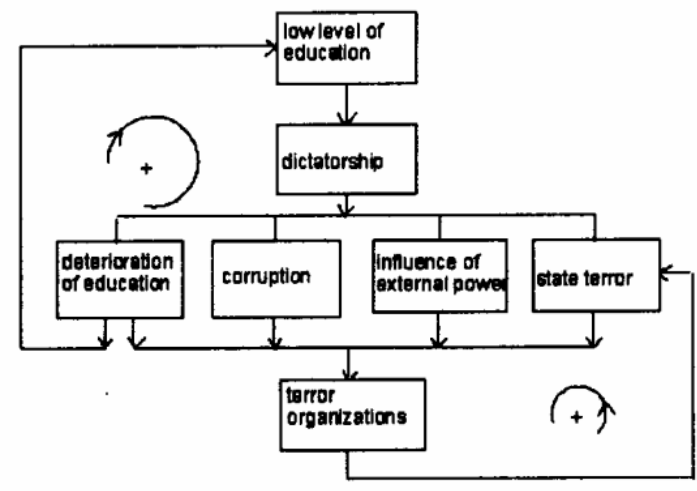

(a)

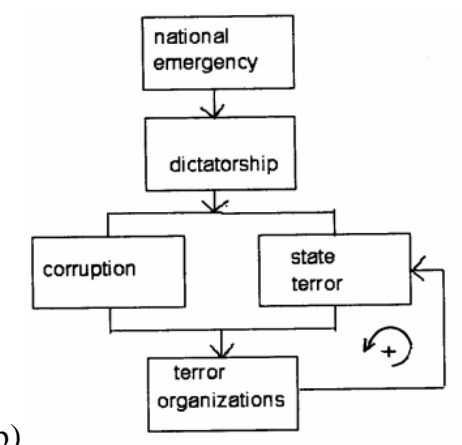

Fig. VII. Structural models of a dictatorial state: (a) in a developing country; and (b) in a developed country (Mansour, 2002).

It should be noted, however, innovated and specifically tailored analysis techniques for both phenomenalistic and structural modelling are needed in order to respond to the new challenges of applications to social systems in the globalization age (Dimirovski, 2004a). 
The real-life experience during the last couple of decades, in particular, and indeed the entire period following World War II, is sufficient to observe how science and technology do not remain neutral, regardless of human endeavours and how humanisticly they were initially conceived. The primary motivation may be tightly linked with competition and with a tendency for prestigious positions within competition at best, and hence preconditioned by a given human society and its features. This, in turn, enhances conflicts of interest leading to crises (Mansour, 2001; Dinibütün and Dimirovski, 2001). It is apparent that new system features and paradigms, as pointed out in the preceding discussion and in part illustrated by Figure VI, do require a more sophisticated use of modelrepresentation techniques for complex systems involving qualitative as well as quantitative methods and also using discrete-event system theory, Moreover, the involvement of soft-computing qualitative models and methods in addition to the quantitative ones seems necessary, instrumental, and more promising than initially perceived.

In the area of systems approaches to the issues of developing countries, the IFAC concerted series of DECOM-TT events seem to have been a unique contributing dedicated development recently. Technical contributions to these series may well be inferred from the sessions' titles that comprised the respective technical programs, a brief outline of which is given in the sequel. In addition to the technical contributions, each event of these series has included a set of carefully chosen suitable keynote and plenary lectures, important both for their scientific timeliness and professional impact to enhance sustainable development policies, which served the goal of knowledge and technology transfer to developing countries.

The 2000 conference in Pretoria, South Africa, provided the following plenary talks: challenges of creating and maintaining power infrastructure in Zimbabwe - the role of technology transfer; South African transport policy, strategy and implementation; integrated investment strategy for unlocking economic potential in developing countries; automation in operating telecommunications and support systems; and South African water supply industry, a strategic overview of the activity and cost chain. The 2001 workshop in Ohrid, Macedonia, contributed as plenary talks: aviation infrastructure in developing countries; neural-network orbit prediction for a geostationary satellite; and control incentives for a leader-follower model in communication networks and softcomputing potential. The 2003 workshop in Istanbul, Turkey, presented as plenary talks: active systems a challenge to contemporary engineering; control applications in physics - from control of chaos to quantum control; composite systems control by combined maths-analytical and FS/NN approach; and an approach to increasing safety operation of air and sea transport. The 2004 workshop in Bansko, Bulgaria, provided talks about education for automation in developing countries; remote learning of mechatronics; optimising supervision and control for industrial furnaces: predictive control based design; overview of road traffic control strategies; using transport telematics to help developing countries achieve a more sustainable transport infrastructure; macro-system models of flows in communication-computing networks; a DESsupported agent-based control architecture for flexible manufacturing systems.

The technical program of the 2000 conference in Pretoria (Craig and Camisani-Calzolari, 2001) included the following sessions: energy management; intelligent transportation systems - a reality; bed modular reactors; European experiences in ITS applications; power systems; vehicle identifications technologies; technology transfer in developing countries; water systems; telecommunications - system design and implementation; measurement and control; advanced control applications; education. The 2001 event in Ohrid (Dimirovski, 2001b) has contributed the following technical sessions: analytical and computational intelligence techniques for estimation, modelling and identification; maths-analytical techniques for systems control and supervision; maths-analytical and computational intelligence techniques for systems control and supervision; computer control and supervision in telecommunications; industrial CIM automation and robotics; upgrading industrial automation and control infrastructure; industrial control and supervision in power plants and systems; control, management and monitoring in earth's environment; complexity and recognition in system modelling and solving; education, continuing education and re-training. The 2003 workshop in Istanbul (Dimirovski and Istefanopulos, 2004) in part expanded on the previous topics with sessions on: analytical control system methodologies; intelligent control system methodologies; manufacturing automation and robotic systems; automation of public buildings and service systems; upgrading industrial automation and control systems; automation and control of electrical power systems; management decisions and decision support systems; and miscellaneous control applications and system designs. It has initiated new subjects in the following sessions: control and management in transportation systems; modelling, simulation and identification; information and communication technologies; advanced controls; intelligent systems; decision making and optimization; control and management of power and water systems; production, automation and robotics; bio and medical system control. The 2004 workshop in Bansko (Sgurev and Co-authors, 2004) made additional extension within the same set of topics, which were introduced in the previous three events, 
by expanding the issues discussed with an emphasis on both regional and global aspects of knowledge and technology transfer.

For quite some time, a series of symposia has been explored bridging the gap between economics and technology and engineering, and in particular how to expand systems engineering technology into applications in business and economy systems. These explorations have been encompassing and combining areas of research in econometrics, statistics, computer science, artificial intelligence and other useful tools for decision and control. In business and economic systems, from the initial focus on branch econometric models, probabilistic models and time-series analysis for optimal decision and management, the focus has shifted to agentbased techniques, AI decision support systems, and spatial data analysis for planning and control as well as financial engineering, market dynamics, pricing theory applications and integrated virtual enterprises (Luenberger, 2002; Neck, 2003). In particular, recently rather rapid new developments in theory, technology and applications have taken place and have brought about the use of so-called softcomputing (Zadeh, 1999, 2001; Yager 2004) based methods and models in decision making for managing organizations (e.g., see Wang and Archer, 1998), in modelling financial system dynamics (e.g., see Andreeski and co-authors, 2003; Special Issue on Neural Networks in Financial Engineering, 2001), and the respective management decision making (e.g., see Luenberger, 2002; Pete and co-authors, 1998; Special Issue on Neural Networks in Financial Engineering, 2001).

The area of social impact of automation, which has emerged from explorations with initial focus on manufacturing enterprises and humanisation of industrial labour, human-machine systems, and teleoperation of robotic mechanisms and systems, has shifted its focus to a deeper understanding of enterprises and human organizations as well as the transformation of industrial systems with its impact on quality of life and labour. Thus this area is becoming more closely related to the area of business and economic systems and management decision making in economic systems. One of the recent outcomes (Martensson and Cernetic, 2002) is on systematic research studies in the area of the social impact of automation. What is now recognized as enterprises based on the ACT paradigm is, in fact, related to and results from the principle of humanoriented system re-design of modern integrated enterprises as a complex organizational system essentially relying on and supported by automation and control systems (e.g., see Brandt and Cernetic, 1998; Brandt and co-authors, 1999).

The other directions of research activities in humanoriented redesign have yielded some outstanding results on emerging technology of automated systems based on human skills and knowledge (Stahre and Martensson, 2004). In turn, these are closely related to the recent developments in costoriented automation and manufacturing systems technologies (Bernhardt and Erbe, 2002; Zaremba and co-authors, 2004). Moreover, these are also closely related to SME business and economic systems (Kopacek, 2004 a, b). However, the research on problems of efficient integration of control and management in large-scale enterprises has given rise to a new direction in systems engineering technology (Morél and co-authors, 2004) referred to as performance oriented system engineering, in which properties such as availability, cost, maintainability, productivity, and reliability become crucial for operating the designed system.

\section{FORECASTS FOR THE NEAR FUTURE}

The essentially interdisciplinary character and nature of social systems has enhanced numerous developments of specific models and techniques. This, in turn, has contributed to systems and control science in terms of appropriate systems approaches applied to human centred and social systems based on exact scientific methods that were borrowed from control and management decision making. Positive effects from globalization may be reasonably expected only if the negative external effects are correctly internalised into the decisions and activities of all people and into the trade-offs that form the basis of these decisions to manage the transitions of the social system in question.

Developments as well as activities in control education apparently have been well defined, considerably matured, and flexibly established for quite some time and continue to progress well. Hence, these developments are likely to continue along the lines of the previous ones in the foreseeable future,. In particular, activities have been largely defined and designed so as to always face the timely challenges emerging from advances in theory, applications and technology of control systems, although some issues concerning the theory-practice gap do not seem to have been addressed. Thus, further improvements of methodological approaches and techniques of teaching, more effective teaching laboratories, internet based learning, etc. (Dormido, 2002; Gentil, 2004), on the one hand, and further explorations of the effective role of international inter-university consortia (Romanovsky and coauthors, 2004) and the creation and running of virtual departments in systems and control engineering (Rudas and co-authors, 2001; Dimirovski, 2004 b), on the other, are yet to be sough. The most recently proposed project (Vlacic, 2003) is devoted to thoroughly exploring the past, present and future of control education, encompassing the following tasks: collection of excellent talks/papers on control education in 
traditional engineering curricula; collection of excellent talks/papers on control education in nontraditional engineering curricula; collection of excellent talks on control education for high school students and teachers; a survey on education technologies and related education concepts. When carried out and accomplished to the full, it is believed, this project will generate a new set of comprehensive, longer-term forecasts.

Problems of international stability, motivated by the stability implications of new developments in control technology and the issues of sustainable global development, constitute an area of common concern to mankind in both socio-economic and sociopolitical terms as well as in the sense of striving for technological development. As we move deeper into the 21 st century, technological developments seem to outpace efforts to place these developments in a societal context before they are initiated. The prevailing mentality for technological development is that of a bold general who won battles by fighting under the motto "Get there first with the most." (Kile, 2004; in reference to the American Civil War). If we continue to allocate resources for technological change according to a war-like mentality, we should anticipate that societal tensions (and wars) both across social divides and within social groups will rise hence instability will also rise. The idea of "first with the most" is based on a competitive notion, which has driven tensions steadily upward following the end of the Cold War. This rise in tensions, both within nations and among societal groups, has surprised most observers, and scientists in the first place, who expected "peace and stability" to follow the end of the bipolar world. Although the global background is not controllable, human activities affect and, to a limited extent, shape changes in this background. Almost all human activity is dynamically linked with this background. Such problems of systems control certainly are outside the scope of traditional math-analytical control theory. International social stability may be unachievable if the global background for human activity changes too rapidly for our social and technical systems to adapt. The setting of global-scale development and international stability represents a complex network of systems the background causes and effects of which are only partially identifiable and partially controllable (Dimirovski, 2001a). The search for new paradigms for system approaches to these problems has just begun.

Nonetheless, there are some concepts and ideas to remedy these critical observations for guiding future advances in control technology toward socially helpful paths. True, many of these ideas were foreshadowed in the past, in earlier proposals (Kile, 2004). These are outlined below.

Introducing the appropriate actions can enhance future stability. Many actions taken in the 20th century to reduce socio-economic imbalances postponed problem solutions rather than creating alternative social behaviours likely to reduce underlying problems. This pattern feature has to be explored and altered as appropriate.

Introduce proper aid initiatives. Technical solutions have been more palliative than tension-reducing. Financial initiatives to reduce poverty have led to increases in populations dependent on these initiatives, creating cycles of dependence, which need to be remedied.

Definitely suppress the source of arms races for good. Perceived imbalances in armaments, especially nuclear weapons and delivery systems, led to "corrective action" by a party which felt threatened. These "corrective actions" created a nuclear arms race which terrorized the entire world for decades. The resulting stocks of weapons have become an intolerable burden for almost everyone and now may seriously become available for terrorism.

Introduce strategy change to food supply. As known, when "miracle rice" was developed, the demand for fertilizers grew. In recent years, population growth has not kept pace with food production so that regional shortages are emerging. These shortages create pressures for further increases in food production.

Impact of automation and machine-assisted thinking. We, control engineers, have indicated in recent papers how labour-saving aspects of automation have affected labour markets. Worker re-training has not kept pace with the need for new skills. This has led to the phenomenon that newer technology jobs are filled by younger, lower-paid workers while older workers become unemployed or work at reduced skill levels. Ranks of unemployed or underemployed workers increase rapidly during times of economic contraction. New jobs are created slowly during economic expansions. The term "jobless recovery" reflects this development and requires novel system approaches to handle it.

The issues and specific problems related to developing countries, being closely related to global development and international stability, constitute a considerable part of the complex network of systems discussed above and the innovative systems approaches to their study. The background causes and effects of the problems related to developing countries are only partially identifiable and partially controllable. Hence the respective forecasts are presented in more detail. Moreover, these have to be addressed within a multi-disciplinary context encompassing all system science areas relevant to Social Systems, and in co-operation with a number of other technical areas on applications of control. In the long run, education is the most important of all society aspects as pointed out in Mansour (2001 a), hence the issues of developing countries largely coincide with the issues of infrastructure 
development (Kopacek, 2004 b, c; Mauro and Franco, 2003; Papageorgiou, 2004) and of combined knowledge and technology transfer (Craig and Camisani-Calzolari, 2001; Dinibütün and Dimirovski, 2001; Dimirovski and Dinibütün, 2003).

Beginning with the development of railways, in contemporary reality the man-made infrastructure systems in almost all fields of human activities, from banking and business through production planning and management to communications (e.g., the internet), either have become or are becoming essentially trans-national. Thus they now require specification of additional constraints and features in the respective representation models and control strategies, which must be observed in resolving the related control and management problems. Contemporary numerical and linguistic information processing (traditional and soft-computing) technologies, employing both qualitative and quantitative model representations, along with communication technologies have fundamentally changed the environment and platforms on which systems are being designed, implemented, deployed, maintained and operated. There exists sound knowledge on how this can be achieved in a way that is consistent with fundamental ethical principles; only world-wide awareness and the gradual practical implementation of the necessary adjustments are lacking. It is within this framework that the future activities on combined knowledge and technology transfer, contributing considerably to the world-wide awareness of how the globalization process can be turned around for the benefit of all nations as well as individuals, are to be sought.

The areas of business and economic systems appear to be simultaneous and mostly influenced by the non-technical phenomena of capital mobility (Glenn and Hannan, 2000) and by the technical phenomena of networked business organizations (Axelrod, 1997; Eeckhout, 2000) and the manufacturing enterprises (Blasi and Ferran, 2002; Chen, 2004), including the concept of virtual enterprises (Molina and Flores, 1999). Furthermore, it is likely that information processing for decision and management in organisations will employ decision support systems (Zimmermann, 1991) that process suitably composed qualitative plus quantitative data collections including exploiting the perceptions manipulation (Yager, 2004; Zadeh, 2002). On the other hand, two problem domains in business and economic systems are likely to continue to be of primary importance: (a) competing or cooperating small and medium-size enterprises (SME; Kopacek, 2004a); and (b) largescale enterprises integration on a trans-national basis (Glenn and Hannan, 2000; Verndat, 1996)). In turn, these trends re-emphasise the importance of improving the models and methods of management group decision making and their applications to cooperating SME and integrated enterprises. Future development of systems approaches to business and economic systems are to be focused on the topics underlying these main trends.

At this stage it is worth pointing out some of the main topics in business and economic systems: (a) Advances in modelling techniques emphasise, among other topics, spatial data set and advanced time-series modelling; advanced econometric modelling; agent-based modelling; and financial engineering models. (b) The use of computational intelligence techniques emphasise intelligent decision support systems; application of artificial neural networks; application of wavelets; methods of genetic algorithms and genetic programming; and computational models based on evolutionary programming. (c) Advances in planning, decision and control emphasise, among other topics, the use of geographical information systems and spatial data analysis; advanced forecasting methods; advanced decision making and management; and applications of optimization and optimal control methods to regional, national and international economies. In particular, robust control theory has recently found several interesting applications in analysing dynamic economic systems under imperfect information. Another very important area of promising applications of control-related techniques is the field of dynamic games, which were and are increasingly used to model dynamic strategic interactions between economic decision makers (Neck 2003). Also SME in manufacturing production (Kopacek, 2004a) and in small-business financial services are gaining in importance, in particular from the point of view of the concept of virtual enterprises (Molina, 1999). Hence, both established activities as well as new challenges of methodology and substance will be within the future. Somewhat paradoxically, the introduction of concepts and methods of control theory into economics during the last four decades has been so successful that they have become part of the advanced economists' toolbox without being recognized as having originated from the control engineering community. For example, see the extensive use of control concepts in the standard text of Ljungqvist and Sargent (2000).

In conjunction with manufacturing systems and enterprise integration, from the computational intelligence employing theorem-proving theory, emerged an important development that is likely to affect business and economic systems as well as the social impact of automation technology in the near future. Namely, development design and deployment of modern integrated industrial control systems has given rise to complex control systems in which the fault-tolerance property as well as availability, reliability, maintainability, and productivity placed more emphasis on the concept of performance oriented systems engineering (Morel and co-authors, 2004). In this new topic, model representations combine discrete-event and discrete-time along with continuous-time system theory in a compatible way 
via employing an approach borrowed from theoremproving techniques in conventional computer science and artificial intelligence (Abrial, 1996; Back, 1979). In addition to the main concern of creating more efficient and/or new manufacturing and production tools and of increasing economic competitiveness, the mutual influence of technology, in general, and automation and control technology, in particular, and the society has always involved the issues of humanising labour on the one hand, and quality of life on the other. Hence, because of its impact on life itself, the relationship of mutual influence between automation technology and society shall continue to expand within human culture and society at large. It should be noted that society environments undergo considerable changes in this globalization age. In the above forecasts and in the previous sections, it has been emphasised that both automation and control technologies play a crucial role in the overall impact of science and technology on contemporary societies.

This impact process continues to be even more intense in the present networked world in the globalization age, but the social impact of automation now exhibits a strong phenomenon of world-wide propagation (Blasi and Ferran, 2002; Glenn and Hannan, 2000). In turn, this phenomenon should be brought into the socio-technical system approach of modelling the social impact of automation in an axiomatic way. In this regard the specific approaches of change-management and success-factor need to be revisited in a broader setting, and the necessary improvements in design concepts of human-oriented manufacturing systems and integrated enterprises need to be further elaborated.

It may well be noted that a number of scientific events dedicated to areas of Social Systems have enhanced bringing to public attention the process by which system concepts and innovative ideas as well as novel developments and results in the respective areas of technical expertise can be exploited to enhance progress in developing countries. Recently the series of such dedicated events appeared to be among the most prominent factors in the dissemination of up-to-date knowledge and experience in the respective areas of technical expertise. They demonstrated by and large the paradigm of international and trans-national cooperation, engagement and dissemination.

All scientific events mentioned in here, which took place under the auspices of the IFAC, have gained good driving momentum, confirming that they are inside the main streams of the respective scientific developments. In summary, this series of events has become a model of response to the challenge of the complexity of competition and cooperation. They serve the objectives in the sense that activities oriented towards developing countries should continue to make their valuable contribution for the positive aspects of globalization to prevail.

\section{CONCLUSION}

The broad area of social systems, which are essentially human and society centred systems, has been overviewed and shown to be a cross-, inter- and multi-disciplinary challenge to systems and control researchers for quite some time. Social systems in modern civilization, currently undergoing its globalization age, are reviewed from the systems science viewpoint and on the grounds of recent developments in control science and technology. Recent developments have put a new emphasis on the social responsibility of the control and automation field during the on-going changes from the cold-war bipolar world to a unipolar one on the way to mankind's multi-polar world of the future.

It may well be argued that the so-called globalization process is not just a contemporary phenomenon but rather a logical, perhaps a natural stage, in the historical development of mankind and its societies due to the developed technological potentials. On the other hand, the real-life world-wide experience during the last two decades or so has clearly demonstrated that technology cannot be considered as neutral within given society environments. In the globalization age, the focus should be on innovated systems approaches, employing new paradigms, to combined knowledge and technology transfer worldwide in general, and to developing countries in particular, that may remedy some of the negative aspects of globalization.

All contemporary societies are more or less networked, and particularly so the main infrastructure systems of business, energy, food, water supply and transportation. Moreover, some of these are already networked on either continental or global scales, which in turn requires more demanding and sophisticated control, coordination and management methodologies and techniques. Hence engineering sciences and technologies cannot be considered as neutral because ultimately all system engineering creations are some kind of socioeconomic system; and this is especially the case for trans-national ones. Furthermore, all the contemporary challenges to global, national and regional development are tied to managing international stability and peace, so they are essentially system problems albeit of non-causal systems. Hence they cannot be tackled by traditional control theories only, and alternative systems approaches have to be developed. This need for new approaches must be especially observed as we look beyond 2005 in conjunction with developing countries and related issues for mankind today.

Nowadays, the sophistication of the control field encompasses the synergy of computational power 
and advanced systems and control theories, thereby enabling new systems engineering methodologies which exploit combined qualitative (linguistic) information in addition to the quantitative (numerical) information as an alternative representation of non-linear and uncertain dynamical processes. These emerging soft-computing modelling techniques have contributed in particular to the paradigm of combined qualitative-quantitative information processing. Thus the challenge of managing relevant scientific activities and enhancing world-wide research in combined knowledge and technology transfer for development is made even more delicate and important.

"... We have to walk the path from the tree of knowledge to the control of destiny." - Jean-Marie Lehn, Nobel Prize laureate, on the occasion of the announcement of Encyclopaedia of Life Support Systems. However, if the control of destiny is hopefully to succeed, remedial actions generated by mankind's science and technology must operate efficiently on a time scale in line with the complex dynamics of the contemporary economy based globalization of world-wide networked societies.

Finally, it is important to note all the above discussed problems in social systems, because of their very nature of human and society centred systems, are indeed strongly interacting and mutually influence each other. Hence a rather timely need is to enhance "cross-boundary" fertilization of both the existing and newly developed approaches and techniques.

\section{ACKNOWLEDGEMENT}

Authors would like to express their gratitude to IFAC colleagues who reviewed this milestone paper, and whose suggestions helped considerably to improve the quality of presentation.

\section{REFERENCES}

Abrial, J. R. (1996). The B Book: Assigning Programs to Meanings. Cambridge University Press, Cambridge.

Aldrich, H. E. (1979). Organizations and Environments. Prentice Hall, Englewood Cliffs, NJ.

Andreeski, C. J., G. M. Dimirovski and G. Petreski (2003). A case study of post-stabilization inflation dynamics via neural-nets approach. In: Proceedings of the IEEE International Conference on Computational Cybernetics ICCC 2003 (I. J. Rudas, K. Hirota and A. Szakal (Eds)), August 29-31, Siofok, HU, pp. 123-130. The IEEE, Piscataway, NJ, and Budapest Polytechnic, Budapest, HU.

Astroem, K. J. (1999). Automatic control: The hidden technology. In: Highlights of European
Control Conference ECC'99 (P.M. Frank (Ed)), pp. 1-28. Springer-Verlag, Berlin, DE.

Axelrod, R. (1997). The Complexity of Cooperation - Agent-Based Models of Competition and Collaboration. Princeton University Press, Princeton, NJ.

Back, R. J. R. (1979). On correct refinement of programs. J. of Computer \& System Sciences, 23, no. 1, pp. 49-68.

Beniger, J. R. (1986). The Control Revolution. Harvard University Press, Cambridge, MA.

Bernhardt, R. and H.-H. Erbe, Editors (2002). Cost Oriented Automation - Low Cost Automation 2001. Pergamon Elsevier Science Ltd, Oxford, UK.

Bitanti, S., and G. Picci, Editors (1996), Identification, Adaptation, Learning. NATO ASI Series F on Computer and Systems Sciences, Volume 153. Springer-Verlag, Berlin, DE

Blasi, A. D. and V. P. Ferran (2002). Conditions for successful automation: A point of view. IFAC b'02 - Plenary Papers, Survey Papers and Milestones, pp. 19-33. The IFAC and Comité Espanol de Automatica, Barcelona, ES.

Bloch, A. (2000). Technologies transfer to a developing country: the road to industrialization. In: Preprints of IFAC Conference on Technology Transfer in Developing Countries - Automation in Infrastructure Creation (DECOM-TT 2000) (I. K. Craig, G. P. Hancke and F.R. CamisaniCalzolari (Eds)), pp. 161-166. The IFAC and the South African Council for Automation and Computation, Pretoria, ZA.

Brandt, D., K. Henning and G. Strina (1999). Human-oriented enterprise modelling and change processes. In: Preprints of $14^{\text {th }}$ World Congress of IFAC (H.-F. Chen, D.-Z. Cheng and J.-F. Zhang (Eds)), Vol. A, pp. 121-126. Pergamon Elsevier Science Ltd, Oxford, UK.

Brandt, D. and J. Cernetic (1998). Human-centred approaches to control and information technology: European experiences. AI \& Society, 12, pp. 2-20.

Buchanen, J. T. (1982). Discrete and Dynamic Decision Analysis. John Wiley, New York.

Chen, D. (2004). A reference model for enterprisecontrol system integration - overview on a standardisation initiative. In: Preprints of the $7^{\text {th }}$ IFAC Symposium on Cost Oriented Automation, (M. Zaremba, J. Sasiadek and H.-H. Erbe (Eds)) Gatineau, June 7-9, pp. 141-146. The IFAC and Université du Québec en Outaouais, Gatineau, CD.

Chestnut, H. (1984). Uses of system techniques to improve the international stability. In: Proceedings of the $1^{\text {st }}$ IFAC Symposium on Supplemental Ways to Improve International Stability, Laxenburg, pp. 87-92. Pergamon Press, Oxford, UK.

Coales, J. F. and M. Seaman (1995). Effective ways of achieving the new world order. In: Preprints of the $5^{\text {th }}$ IFAC Conference on Supplemental 
Ways to Improve International Stability (P. Kopacek (Ed)), paper SU-02. The IFAC and Institute of Handling Devices and Robotics, Technis che Universität Wien, Vienna, AT.

Craig, I. K. and F. R. Camisani-Calzolari, Editors (2001). Technology Transfer in Developing Countries - Automation in Infrastructure Creation (DECOM-TT 2000). Pergamon Elsevier Science Ltd., Oxford, UK.

Cuénod, M. A. and S. Kahne, Editors (1973). Systems Approaches to Developing Countries. The IFAC and the ISA, Pittsburgh, PA.

Dimirovski, G. M. (1988). YU National Document on Information Based Technologies to InterGovernmental Conference of Experts on New and High Technologies of the Non-aligned and Developing Countries - New Delhi. Federal Ministry for Technological Development of S.F.R. of Yugoslavia, Belgrade.

Dimirovski, G. M. (2001a). Applied system analysis to transition crisis of Southeast Europe and new national goals formation. In: Conflict Management and Resolution in Regions of Long Confronted Nations (G. M. Dimirovski (Ed)), pp. 85-93. Pergamon Elsevier Science Ltd., Oxford, UK.

Dimirovski, G. M., Editor (2001b). Automatic Systems for Building the Infrastructure in Developing Countries 2001. Elsevier Science Ltd., Oxford, UK.

Dimirovski, G. M. and Y. Istefanopulos, Editors (2004). Automatic Systems for Building the Infrastructure in Developing Countries (DECOM-TT 2003). Elsevier Science Ltd., Oxford, UK.

Dimirovski, G. M. and A. T. Dinibütün (2003) Technology transfer to developing countries and technological development for social stability Part 2. In: Preprints of the $9^{\text {th }}$ IFAC Workshop on Supplemental Ways for Improving International Stability, (P. Kopacek and L. Stapleton (Eds)), Waterford, July 3-5, pp. TIS03-07Fr(1-6). The IFAC and Waterford Institute of Technology, Waterford, IR.

Dimirovski, G. M. (2004a). IFAC Beyond 2005 Emerging Areas: A DECOM Based Proposal on Control and Management in Transnational Systems (Document submitted to the TB via the CC 9 Chair). IFAC Secretariat, Laxenburg, AT.

Dimirovski, G. M. (2004b). Towards virtual university department: Running a graduate program via Internet. In: Proceedings of the $5^{\text {th }}$ IEEE International Conference on Information Technology Based Higher Education and Training (O. Kaynak, Y. Akpinar and M. 7). Bogazici University, Istanbul, TR, and the IEEE, Piscataway, NJ.

Dinibütüm, A. T. and G. M. Dimirovski (2001). Technology transfer to developing countries and technological development for social stability Parts1. In: Preprints of the $8^{\text {th }}$ IFAC Workshop on Supplemental Ways for Improving
International Stability (P. Kopacek and M. W. Han (Eds)), pp. 25-26. The IFAC and Institute für Handhabungs Gerette und Robotik, Technische Universitaet Wien, Vienne, AT.

Dormido Bencomo, S. (2002). Control learning: Present and future. In: IFAC b'02 - Plenary Papers and Milestones (E. F. Camacho, L. Basanez and J. A. de la Puente (Eds)), pp. 81103. The IFAC and Comité Espanol de Automatica, Barcelona.

Dormido, S. and F. Morilla, Editors (2002). Internet Based Control Education. Elsevier Science Ltd., Oxford, UK.

Eeckhout, J. (2000). Competing Norms of Cooperation. Department of Economics, University of Pennsylvania, Philadelphia, PA.

Gardenfors, P. (2000). Conceptual Spaces: The Geometry of Thought. MIT Press, Cambridge, MA.

Gardner, H. (1985). The Mind's New Science: A History of Cognitive Revolution. Basic Books, New York.

Gentil, S., Editor (2004). Preprints of the IFAC WS on Internet Based Education IBCE'04, Grenoble, September 57. The IFAC, and INP and UJF de Grenoble, Grenoble, FR.

Gibson, J. L., J. M. Ivancevich and J. H. Donnelly Jr (1997). Organizations: Behavior, Structure, Processes. Irwin, Homewood, IL and Boston, MA.

Glenn, C. and M. Hannan (2000). Demography of Corporations and Industries. Princeton University Press, Princeton, NJ.

Goicoechea, A., D. R. Hanson and L. Duckstein (1982). Multi-objective Decision Analysis with Engineering and Business Applications. John Wiley, New York.

Groumpos, P. P. (2000). Report on the IFAC 1999 Panel on Control Challenge in the $21^{\text {st }}$ Century. ICIMS News, no. 22, pp. 7-11, January, University of Patras.

Harary, F., R. Z. Norman and D. Cartwright (1965). Structural Models: Introduction to the Theory of Directed Graphs. John Wiley, New York.

Hersh, M. A. (2000). Environmental ethics for engineers. Engineering Science and Education, 9, pp. 13-20.

Hersh, M. A. (2001). The ethics of military work: A guide for scientists and engineers. In: Conflict Management and Resolution in Regions of Long Confronted Nations (G. M. Dimirovski (Ed)), pp. 95-106. Elsevier Science Ltd., Oxford, UK.

Hersh, M. A. and W. D. Tucker (2004). Ethics and mono-disciplinarity: positivism, informed consent, and informed participation. Working paper, Department of EEE, University of Glasgow, Glasgow (private communication).

Hillier, F. S. and G. J. Lieberman (1995). Introduction to Operations Research. Holden Day Inc., Oakland, CA. 
Ilyasov, B. (2000). Report on the 1999 Workshop on Problems of Transfer Technology. ICIMS News, no. 22, p. 20, January, University of Patras.

Kile, F. (2001). The road to active peace (Keynote Paper). In: Conflict Management and Resolution in Regions of Long Confronted Nations (G. M. Dimirovski (Ed)), pp. 11-16. Elsevier Science Ltd., Oxford, UK.

Kile, F. (2004). Milestone notes for IFAC TC 9.5 on Supplemental Ways for Improving International Stability - a Proposal to IFAC CC on Social Systems (private communication).

Kilgour, D. M., K. W. Hipel, and L. Fang (1987), Solution concepts in noncooperative games. Large Scale Systems, 6, pp. 49-71.

Kopacek, P. (2001). SWIIS - An important expression of IFAC commitment to social responsibility. In: Conflict Management and Resolution in Regions of Long Confronted Nations (G. M. Dimirovski (Ed)), pp. 17-21. Elsevier Science Ltd., Oxford, UK.

Kopacek, P., Editor (2002). Social Stability: The Challenge of Technology Development. Elsevier Science Ltd, Oxford, UK.

Kopacek, P. and L. Stapleton, Editors (2004). Technology and International Stability Proceedings of SWIIS 2003. Elsevier Science Ltd., Oxford, UK.

Kopacek, P. (2004a). High technology in low cost manufacturing - with emphasis on SME's. In: Preprints of the $7^{\text {th }}$ IFAC Symposium on Cost Oriented Automation (M. Zaremba, J. Sasiadek and H.-H. Erbe (Eds)) Gatineau, June 7-9, pp. 25-32. The IFAC and Université du Québec en Outaouais, Gatineau, CD.

Kopacek, P., Editor (2004b). Preprints of the IFAC Multi-track Conference on Advanced Control Strategies for Social and Economic Systems, Vienna, September 2-4. The IFAC and Institute für Handhabungs Gerette und Robotik, Technische Universitaet Wien, Vienne, AT.

Kopacek, P. (2004 c). Education for automation in developing countries (Plenary Paper). In: Preprints of the IFAC WS on Automatic Systems for Building the Infrastructure in Dveloping Countries - Regional and Global Aspects (V. Sgurev, G. Dimirovski, and M. Hadjiski (Eds)), pp. 1-5. The IFAC and Bulgarian Union of Automation and Informatics, Sofia, BG.

Kosko, B. (1993). Fuzzy Thinking. Hyperion, New York.

Küng, H. (1990). Projekt Weltethos. Piper GmbH, Munich.

Levin, R. I., D. S. Rubin, J. P. Stinson and E. S. Gradner Jr (1992). Quantitative Approaches to Management. McGraw-Hill, Inc, New York.

Lindfors, L., Editor (2004). Advances in Control Education. Pergamon Elsevier Ltd, Oxford, UK.

Ljungqvist, L. and T. Sargent (2000). Recursive Macroeconomic Theory. MIT Press, Cambridge, MA.
Luenberger, D. G. (2002). Systems concepts in financial pricing theory. In: IFAC b'02 Plenary Papers, Survey Papers and Milestones, pp. 11-18. The IFAC and Comité Espanol de Automatica, Barcelona, ES.

Mansour, M. (2001a). Systems theory and human science (Invited Plenary Paper). In: Conflict Management and Resolution in Regions of Long Confronted Nations (G.M. Dimirovski (Ed)), pp. 1-10. Elsevier Science Ltd., Oxford, UK.

Mansour, M. (2001b). System concept modelling in human systems (Invited Plenary Paper). In: Preprints of the $8^{\text {th }}$ IFAC Workshop on Supplemental Ways for Improving International Stability (P. Kopacek and M. W. Han (Eds)), pp. 13-16. The IFAC and Vienna University of Technology Institute of Handling Devices and Robotics, Vienna.

Mansour, M. (2002). The fundamentals of modern civilization: consequences and remedies. Working paper, Institute of Automatic Control, Swiss Federal Institute of Technology ETH, Zurich (private communication).

Martensson, L. and J. Cernetic (2002). IFAC 2002 milestone report on social impact of Automation. In: IFAC b'O2 - Plenary Papers, Survey Papers and Milestones, pp. 219-226. The IFAC and Comité Es panol de Automatica, Barcelona, ES.

Martin, M.W. and R. Schinzinger (1996). Ethics in Engineering ( $3^{\text {rd }}$ ed.). McGraw-Hill, New York.

Mauro, V. and G. Franco (2003). Using transport telematics to help developing countries to achieve more sustainable transport infrastructure. In: Preprints of the 4th IFAC WS on Automatic Systems for Building the Infrastructure in Developing Countries Regional and Global Aspects (V. Sgurev, G. Dimirovski and M. Hadjiski (Eds)), pp. 41-46. The IFAC and Bulgarian Union for Automation and Informatics, Sofia, BG.

Mishau, F., S. Gentil and M. Barault (2001). Expected benefits of web-based learning for engineering education: Examples in control engineering. European J. of Engineering Education (SEFI), 26, no. 2, pp. 151-168.

Molina, A. and M. Flores (1999). A virtual enterprise in Mexico: From concepts to practice. J. of Intelligent \& Robotic Syst., 26, 289-302.

Morel, G., D. Mery, J. B. Leger, and T. Lecompte (2004). Performance oriented system engineering: Rationales, experiments, and open issues (Invited Plenary Paper). In: Preprints of the $7^{\text {th }}$ IFAC Symposium on Cost Oriented Automation (M. Zaremba, J. Sasiadek and H.-H. Erbe (Eds)), Gatineau, June 7-9, pp. 15-24. The IFAC and Université du Québec en Outaouais, Gatineau, CD.

Myerson, R. B. (1991). Game Theory: Analysis of Conflict. Harvard University Press, Cambridge, MA. 
Neck, R., Editor (2003). Modelling and Control of Economic Systems - SME 2001. Elsevier Science Ltd., Oxford, UK.

Neck, R. (2003). Dynamic game theory: Modeling international and national economic strategic interactions. In: Control Applications of Optimisation 2003 (R. Bars and E. Gyurkovics (Eds)), pp.87-98. Pergamon Elsevier Ltd, Oxford

Papageorgiou, M. (2004). Overview of road traffic control strategies (Plenary Paper). In: Preprints of the 4th IFAC WS on Automatic Systems for Building the Infrastructure in Developing Countries - Regional and Global Aspects (V. Sgurev, G. Dimirovski and M. Hadjiski (Eds)), pp. 29-40. The IFAC and Bulgarian Union of Automation and Informatics, Sofia, BG.

Pete, A., K. R. Pattipati, D. L. Kleinman and Y. N. Levchuk (1998). An overview of decision networks and organizations. IEEE Trans. on Systems, Man \& Cybernetics - Pt. C: Applications and Reviews, 28, no.2, pp. 173-193.

Romanovsky, G. F., G. Eisen, Yu. P. Kondratenko and S. A. Sydorenko (2004). Higher Education Perspectives: The Role of Inter-University Consortia. Regional Inter-University Centre, Mykolaiv, UA.

Rudas, I. J., L. Horvath and G. M. Dimirovski (2001). The $21^{\text {st }}$ century education: Advancements towards virtual university. In: Automatic Systems for Building the Infrastructure in Developing Countries 2001 (G. M. Dimirovski (Ed)), pp. 233-237. Pergamon Elsevier Science Ltd, Oxford, UK.

Russell, B. (1945). A History of Western Philosophy. Simon and Schuster, New York.

Russell, B. (1975). Power. Unwin Books, London.

Schefran, J. (2001). Power distribution, coalition formation and multipolar stability in international systems: Case study of Southeastern Europe. In: Conflict Management and Resolution in Regions of Long Confronted Nations (G. M. Dimirovski (Ed)), pp. 37-48. Elsevier Science Ltd., Oxford, UK.

Sgurev, V., G. M. Dimirovski and M. Hadjiski, Editors (2004). Preprints of the 4th IFAC WS on Automatic Systems for Building the Infrastructure in Developing Countries Regional and Global Aspects (DECOM-TT 2004), Bansko, October 3-5. The IFAC and Bulgarian Union of Automation and Informatics, Sofia, BG.

Special Issue on Neural Networks in Financial Engineering (2001). IEEE Trans. on Neural Networks, 12, no. 4, July.

Stahre, J. and L. Martensson, Editors (2004). Automated Systems Based on Human Skill and Knowledge. Elsevier Science Ltd., Oxford.

Stinchombe, A. L. (1990). Information and Organizations. University of California Press, Berkeley, CA.
UNESCO (2002). Encyclopaedia of Life Support Systems: Knowledge for Peace, Progress and Sustainable Development. UNESCO and EOLSS Publishers, Oxford, UK.

Verndat, F. B. (1996). Enterprise Modelling and Integration. Chapman \& Hall, London - New York.

Vlacic, L. and R. Brisk (2001). Advances in Control Education. Pergamon Elsevier Ltd, Oxford.

Vlacic, L. (2003). Proposal for Special Projects on Control Education in Conjunction with IFAC Congress 2005 and the $50^{\text {th }}$ Anniversary of the IFAC. IFAC Secretariat, Laxenburg, AT.

Wang, S-H. and N. P. Archer (1998). A neural network based fuzzy set model for organizational decision making. IEEE Trans. on Systems, Man \& Cyber. - Pt. C: Applications and Reviews, 28, no. 2, pp. 194-203.

Wagner, R. H. (1994). Peace, war and the balance of power. American Political Science Review, 88, no. 3, pp. 593-607.

Yager, R. R. (2004). Intelligent decision making and information fusion. In: Proceedings of the $2^{d d}$ IEEE Conference on Intelligent Systems (R. R. Yager and V. S. Sgurev (Eds)), pp. 14. The IEEE, Piscataway, NJ.

Zadeh, L. A. (1984). Fuzzy Sets and Commonsense Knowledge. Cognitive Science Report 21, University of California, Berkeley, CA.

Zadeh, L. A. (1996). Fuzzy logic = computing with words. IEEE Trans. on Fuzzy Systems, 4, no. 2, pp. 103-111.

Zadeh, L. A. (1999). From computing with numbers to computing with words - From manipulation of measurements to manipulation of perceptions. IEEE Trans. on Circuits \& Systems - I. Fundamental Theory \& Applications, 45, no. 1, pp. 105-119.

Zadeh, L. A. (2002). Toward a perception based theory of probabilistic reasoning with imprecise probabilities. J. of Statistical Planning \& Inference, 105, pp. 233-264.

Zaremba, M., J. Sasiadek and H.-H. Erbe, Editors (2004). Preprints of the $7^{\text {th }}$ IFAC Symposium on Cost Oriented Automation, Gatineau, June 79. The IFAC and Université du Québec en Outaouais, Gatineau, CD.

Zimmermann, H.-J. (1991). Fuzzy Sets, Decision Making and Expert Systems. Kluwer Academic, Boston, MA.

Zimmermann, H.-J. (1998). Fuzzy Data Analysis. In: Computational Intelligence: Soft-Computing and Fuzzy-Neuro Integration with Applications (O. Kaynak, L. A. Zadeh, B. Türksen and I. J. Rudas (Eds)), Chapter 5.2, pp. 381-402. NATO ASI Series F on Computer and Systems Sciences, Volume 162. Springer-Verlag, Berlin, DE. 